\title{
FLOTAÇÃO DE SILICATOS
}

MENDES, M. V. A. ${ }^{12^{*}}$; CANANÉIA, H. L. M. ${ }^{1}$; NEIVA, I. B. ${ }^{1}$; MACHADO, L. A. ${ }^{1}$; CORREA, L. A. ${ }^{1}$

${ }^{1}$ Universidade Federal de Goiás (UFG) - Departamento de Engenharia de Minas

${ }^{2}$ Serviço Nacional de Aprendizagem Industrial (SENAI) - Departamento de Mineração - Escola SENAI Catalão/GO *marcos.vinicius.agapito@gmail.com

Submetido 28/06/2018 - Aceito 22/07/2018

DOI: $10.15628 /$ holos. 2018.7440

\section{RESUMO}

Os silicatos são minerais de maior abundância na litosfera, sua flotação apresenta certa complexidade por conter seis tipos de classes de acordo com a sua estrutura cristalina. O objetivo do presente artigo é revisar bibliograficamente o processo de flotação de silicatos, uso de coletores e aplicações. Os principais reagentes utilizados na flotação são a amina e o ácido carboxílico, mas estudos recentes indicam que as misturas entre coletores contribuem para a sinergia da ação destes. Devido ao alto custo da amina, alguns estudos recentes mostram que esta pode ser substituída parcialmente por espumante ou ainda totalmente por óleo diesel.

PALAVRAS-CHAVE: Flotação; Silicatos; Amina.

\section{FLOTATION OF SILICATES}

\section{ABSTRACT}

The silicates are the minerals with most abundance in the lithosphere. Their flotation exhibits some difficulty, because, they have six classes which differ by their crystalline structure. This article intent to make a bibliographic review the flotation process of silicates, use of collectors and applications. The reagents most used in this flotation are amine and carboxylic acid, but recent researches suggest that the collector's combination contribute to optimize their function. On account of the amine's expensive price, some recent studies show that these can be partially replaced by a foaming or totally replaced for diesel oil.

KEYWORDS: Flotation; Silicates; Amine. 


\section{INTRODUÇÃO}

Os minerais silicáticos, que representam $98 \%$ da crosta terrestre, geralmente apresentamse como minerais de ganga (sem valor econômico) no tratamento de minérios. Por conta da sua abundância na crosta terrestre, há uma variedade muito grande de minerais desse grupo. De acordo com dados do Sumário Mineral (DNPM, 2015), o único silicato classificado como minério e concentrado a partir do processo de flotação, é a vermiculita. Este importante mineral minério demonstra crescimento em sua utilização nos últimos anos, como é possível notar no gráfico apresentado na Figura 1. Ainda considerando os dados apresentados pelo Sumário Mineral, Goiás foi o principal estado produtor de vermiculita em 2014, correspondendo a 92,1\% da produção nacional.

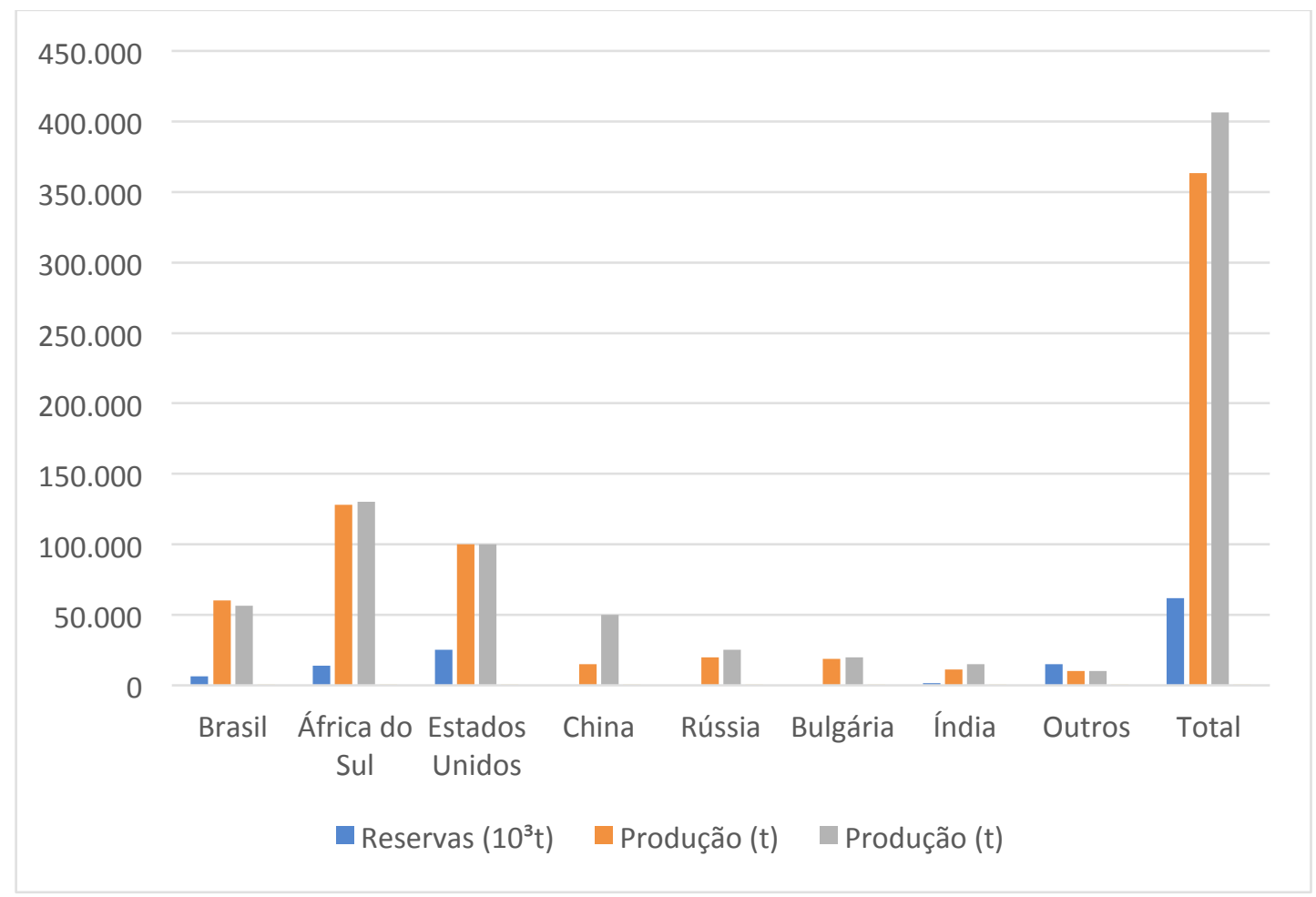

Figura 1: Reservas e produção mundial de vermiculita em 2013 e 2014 . Fonte: Sumário Mineral - DNPM (2015).

A flotação dos silicatos tem certa complexidade, pois vários outros minerais apresentam similaridade mineralógica. Eles são subdivididos em seis classes de acordo com o arranjo dos tetraedros de silício e a relação de silício e oxigênio, sendo elas: nesossilicatos, sorossilicatos, ciclossilicatos, isossilicatos, filossilicatos e tectossilicatos (Tabela 1). Para cada classe é utilizado um tipo de coletor diferente no processo de flotação (Chaves, 2013). 
Tabela 1: Classes de divisão dos silicatos. Fonte: Adaptado de Chaves (2013).

\begin{tabular}{c|c|c|c|c}
\hline Classe & $\begin{array}{c}\text { Átomos de } \\
\text { oxigênio (0) } \\
\text { compartilhados }\end{array}$ & $\begin{array}{c}\text { Arranjo dos } \\
\text { tetraedros }\end{array}$ & $\begin{array}{c}\text { Relação } \\
\text { Si:0 }\end{array}$ & Exemplos \\
\hline Nesossilicatos & 0 & $\begin{array}{c}\text { Independentes, } \\
\text { isolados }\end{array}$ & $1: 4$ & Olivina \\
\hline Sorossilicatos & 1 & Duplos, isolados & $2: 7$ & Hemimorfita \\
\hline Ciclossilicatos & 2 & Anéis & $1: 3$ & Turmalina \\
\hline Inossilicatos & 2 & Cadeias simples & $1: 3$ & $\begin{array}{c}\text { Grupo dos } \\
\text { piroxênios }\end{array}$ \\
\cline { 2 - 5 } & 2,3 & Cadeias duplas & $4: 11$ & $\begin{array}{c}\text { Grupo dos } \\
\text { anfibólios }\end{array}$ \\
\hline Filossilicatos & 3 & Folhas, lâminas & $2: 5$ & Grupo das micas \\
\hline Tectossilicatos & 4 & $\begin{array}{c}\text { Estruturas } \\
\text { tridimensionais } \\
\text { complexas }\end{array}$ & $1: 2$ & Quartzo \\
\hline
\end{tabular}

Considerando que os silicatos estão presentes em assembleia mineral com a maior parte dos minerais-minérios, e devido a necessidade de separação, por vezes realizada com flotação, este estudo tem por objetivo realizar uma revisão bibliográfica acerca da flotação de silicatos, analisando processos, equipamentos, reagentes e tendências no tratamento de minérios.

\section{CLASSIFICAÇÃO DOS SILICATOS}

Cada classe de silicatos possui um arranjo cristalino especifico, permitindo acomodar os átomos de silício ( $\mathrm{Si}$ ) e oxigênio (O). A diferença entre as estruturas cristalinas permite a formação de diferentes minerais.

O grupo dos Nesossilicatos apresentam algumas características, como praticamente não ocorrer quebra dos tetraedros de silício e por conter ponto de carga zero (PZC), isto é, mesma quantidade de cargas elétricas positivas e negativas, na faixa de $\mathrm{pH}$ de 4 a 8 (Fuerstenau \& Pradip, 2005). Alguns exemplos são o topázio, granada e a fenacita. Kwang (2003) menciona que os minerais pertencentes a este grupo tendem a flotar melhor com o uso do coletor aniônico oleato de sódio, quase sempre insensíveis ao $\mathrm{pH}$.

Os sorossilicatos e ciclossilicatos possuem o PZC na faixa de $\mathrm{pH} 3$ a 4 . Além disso, a quebra das ligações silício-oxigênio nos tetraedros de sílica os diferem do grupo dos nesossilicatos. Exemplos dessa classe de minerais são o berilo, turmalina, alanita e cordierita (Chaves, 2013).

O grupo dos Inossilicatos tem cadeia simples ou dupla. Eles possuem muitas ligações silício-oxigênio que quebram em conjunto as ligações cátion-oxigênio. Isso faz com que ocorram superfícies de clivagem hidrofílica e anisotrópica. Em virtude desta situação, o PZC da grande maioria dos Inossilicatos é de pH 3. O espodumênio é um dos minerais representantes desta classe, muito importante para produção industrial de lítio (Viana, Araújo, Peres \& Valadão, 2006). Ainda é importante ressaltar que, os minerais desta classe, não flutuam bem em tanques de flotação quando na presença de um coletor aniônico típico como o oleato de sódio (Kwang, 2003; Klein, 2002). 
Os filossilicatos, ao terem as ligações quebradas, geram superfícies hidrofílicas. A Caolinita e as micas são exemplos de minerais deste grupo, apresentando boa flotabilidade na faixa de $\mathrm{pH}$ 2 a 3, tanto com o coletor aniônico, quanto com o catiônico. Entretanto, um mineral que foge a essa regra é a serpentina, que com o uso de oleato de sódio, flota em uma faixa estreita de pH 9 a 11 (Manser, 1975). Talco e pirofilita, também considerados filossilicatos, com camadas tetraedro-octaedro-tetraedro, apresentam hidrofobicidade naturalmente, sendo necessário somente um espumante para sua flotação com pH de 3 a 6 .

Por fim, Chaves (2013) classifica como tectossilicatos os feldspatos, feldspatóides e quartzos, minerais que envolvem a quebra de tetraedros de sílica ou alumínio, formando superfícies hidrofílicas e PZC com pH de 1,5 a 2,5.

\section{FLOTAÇÃO DE SILICATOS}

Flotação é um processo de separação utilizando princípios de química de superfície dos minerais. Para o sucesso do processo, é necessária a cominuição do minério, permitindo que suas partículas sejam liberadas. A flotação em espuma, bastante comum, é feita em água, na qual algumas partículas das espécies minerais aderem as bolhas de ar que são inseridas na polpa, transbordando, enquanto o restante sedimenta juntamente a água (Wills \& Finch, 2015).

O segregamento de minerais está ligado a afinidade seletiva de suas superfícies, devidamente modificada por reagentes como os coletores, espumantes e modificadores (Gancev, 2009). A flotação acontece em vários estágios, sendo a etapa "rougher" a primeira delas, onde obtém-se um concentrado pobre e um rejeito ainda com mineral-minério. 0 concentrado desta etapa passa por um processo de limpeza, realizado na etapa "cleaner", permitindo adequar as características do concentrado final. O rejeito do rougher segue para etapa "scavenger", que obtém um rejeito extremamente pobre, adequado para deposição em barragens de rejeito. A Figura 2 apresenta um esquema destas etapas, não sendo regra geral. Há possibilidade de mesclar as etapas nos circuitos, acrescentando-se rougher, cleaner e scavenger, de acordo com a necessidade do processamento mineral (Wills \& Finch, 2015).

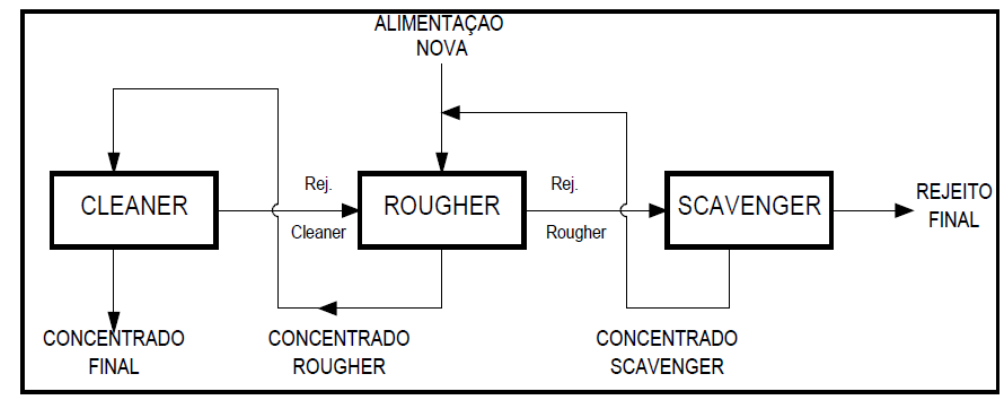

Figura 2: Esquema representativo das etapas de flotação. Fonte: Adaptado de Luz et al (2010).

Os coletores são substâncias que envolvem as partículas e tornam elas capazes de aderirem às bolhas de ar (hidrofóbicas). Sua estrutura molecular caracteriza-se por uma porção molecular covalente e outra iônica, tornando o coletor um surfactante, ou seja, composto com uma estrutura anfipática (Mular, Halbe \& Barratt, 2002). 
Uma substância é dita hidrofóbica quando a sua superfície é apolar, o que indica que a mesma tem atração pelo ar, sendo que poucos minerais possuem naturalmente esta característica, como é o caso da molibdenita, talco, carvão, enxofre e grafita (Luz, Sampaio \& França, 2010). Quando uma substância tem maior afinidade pela fase líquida do que pela fase gasosa, ou seja, possui a propriedade se ser umectada pela água, esta é chamada de hidrofílica.

O ângulo formado entre as superfícies sólidas e líquidas é conhecido como ângulo de contato (Figura 3), onde para superfícies hidrofílicas este ângulo é menor que $90^{\circ}$ enquanto para as superfícies hidrofóbicas o ângulo é maior que $90^{\circ}$. Este ângulo permite identificar o grau de afinidade entre as superfícies (Chaves, 2013).

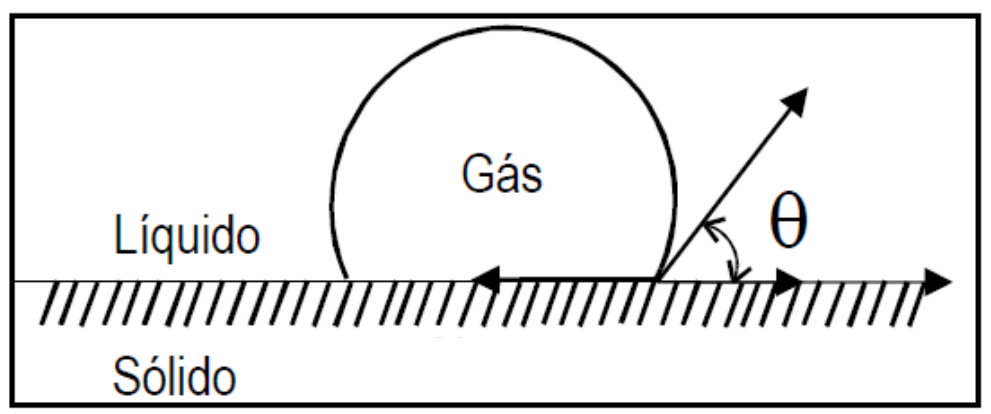

Figura 3: Representação esquemática do ângulo de contato entre as fases. Fonte: Adaptado de LUZ et al (2010).

Os espumantes são reagentes com estrutura molecular formada por um grupo polar, que pode, ou não, ser iônico. Sua função é reduzir a tensão superficial, manter a probabilidade de colisão com as partículas hidrofóbicas e aumentar o tempo de contato da partícula com a bolha após o choque (Gupta \& Yan, 2006).

Modificadores tratam-se de reagentes que adequam a ação efetiva do coletor e aumentam a sua seletividade. Traduzem-se nos reguladores de $\mathrm{pH}$, ativadores e depressores (Baltar, 2008).

Como o quartzo e outros silicatos são geralmente associados a outros tipos de minerais, muitas vezes compõem a ganga de vários processos de beneficiamento. Utiliza-se flotação reversa na separação dos silicatos, que consiste em flotar o mineral de ganga e deprimir o mineral contendo o elemento útil (Wills \& Finch, 2015).

\section{EQUIPAMENTOS DE FLOTAÇÃO}

As máquinas de flotação têm o objetivo de separar os minerais de interesse da ganga. Para tal finalidade, torna-se necessário que reagentes, ar, minerais e fase líquida estejam em contato íntimo. A principal função da máquina de flotação é injetar ar na polpa. Chaves (2013) classifica-as em células mecânicas, pneumáticas, tank cell e colunas de flotação.

Entretanto, antes do material entrar realmente nos equipamentos de flotação, operações auxiliares de atrição/escrubragem (agitação do material para liberação de partículas finas aderidas a partículas maiores de mineral-minério), deslamagem (remoção de partículas finas que podem revolver partículas maiores de mineral-minério e mascarar sua superfície) e condicionamento (mistura de reagentes a polpa mineral para alteração das propriedades de 
superfície das partículas minerais) são necessárias para garantir o perfeito funcionamento do processo (Luz et al, 2010).

\subsection{Células mecânicas}

As células mecânicas são basicamente tanques que recebem a polpa mineral previamente condicionada, possuindo um rotor para agitação do material, mantendo-o em suspensão e permitindo a colisão da bolha com a partícula mineral (Figura 4). Um estator acoplado junto ao rotor permite a quebra da vazão de ar inserida no equipamento, formando bolhas menores e consistentes (Mular et al, 2002).

$O$ ar pode ser aspirado, quando o rotor gera pressão negativa no fundo do tanque, sugando o ar do ambiente externo para formação de bolhas, ou injetado por meio de ventiladores ou compressores (Luz et al, 2010).

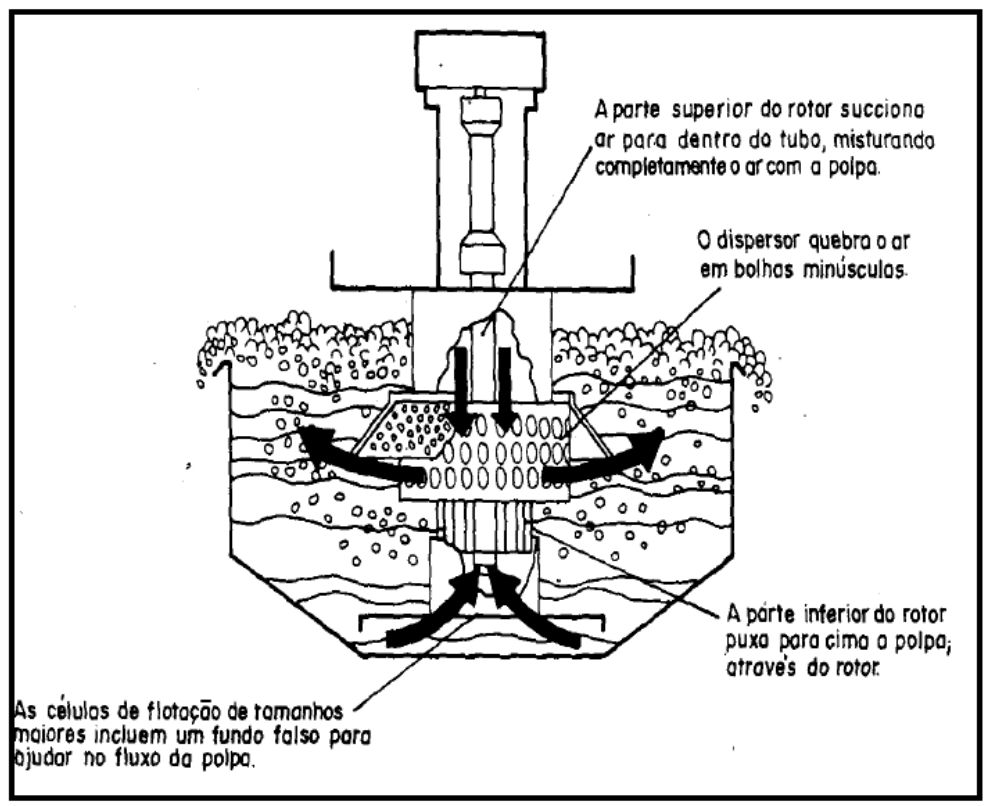

Figura 4: Esquema do funcionamento de uma célula de flotação. Fonte: LUZ et al (2010).

\subsection{Células pneumáticas}

As células pneumáticas não possuem agitação que cause turbulência da polpa no tanque, permitindo a flotação de partículas minerais mais finas. A aeração é feita através da injeção de ar comprimido. Podem ter em sua estrutura tela ou não. Na primeira situação, o ar é injetado na parte inferior do equipamento através de um fundo poroso. As células pneumáticas sem tela possuem injeção de ar na parte superior, de modo a promover intensa circulação da polpa, melhorando as chances da partícula mineral de interesse ser coletada pela bolha (Luz et al, 2010).

\subsection{Tank cell}

Os tanks cell são máquinas de flotação que utilizam a tecnologia de agitadores e condicionadores para promover a agitação da polpa. Possuem agitação mecânica através de 
rotores e diferem das células mecânicas convencionais pela possibilidade de alteração do posicionamento dos rotores em função da etapa de flotação realizada. Deste modo, permitem um melhor controle e eficiente dos processos de flotação realizados (Chaves, 2010).

\subsection{Colunas de flotação}

As colunas são equipamentos de grande capacidade que funcionam sem agitação mecânica, somente com injeção de ar em sua base. Este equipamento trouxe melhorias no processo de flotação. Os concentrados de diversos tipos de minérios foram otimizados. 0 desempenho metalúrgico, custos de capital e operação também tiveram bons resultados. Tais fatores são responsáveis pelo aumento da aplicação de colunas em vários projetos (Queiroz, 2003).

Gupta e Yan (2006) difere a coluna de flotação da célula mecânica convencional em alguns aspectos: a) geometria (maior relação altura/diâmetro); b) existência da água de lavagem; c) ausência de agitação mecânica; e d) sistema de geração de bolhas.

A coluna de flotação é dividida em zona de recuperação e limpeza. A Figura 5 apresenta um esquema dessa divisão. A alimentação da polpa condicionada normalmente é realiza a $2 / 3$ da base.

As partículas entram em contato com as bolhas de ar geradas (distribuídas pelo aerador) na zona de recuperação. Aquelas hidrofóbicas, aderidas às bolhas de ar, são transportadas até a zona de limpeza, e as partículas hidrofílicas, são direcionadas para a base da coluna devido a sedimentação (Luz et al, 2010). A água de lavagem tem por objetivo diminuir o arraste de partículas que não são de interesse, além de estabilizar a espuma (Chaves, 2013).

A colunas normalmente apresentam melhor recuperação mássica e metalúrgica de minerais do que as células mecânicas convencionais, operação estável, pouca manutenção, baixo custo operacionais devido à ausência de partes móveis para sistema de agitação da polpa, melhor área ocupada dentro da usina e um consumo menor de reagentes. 


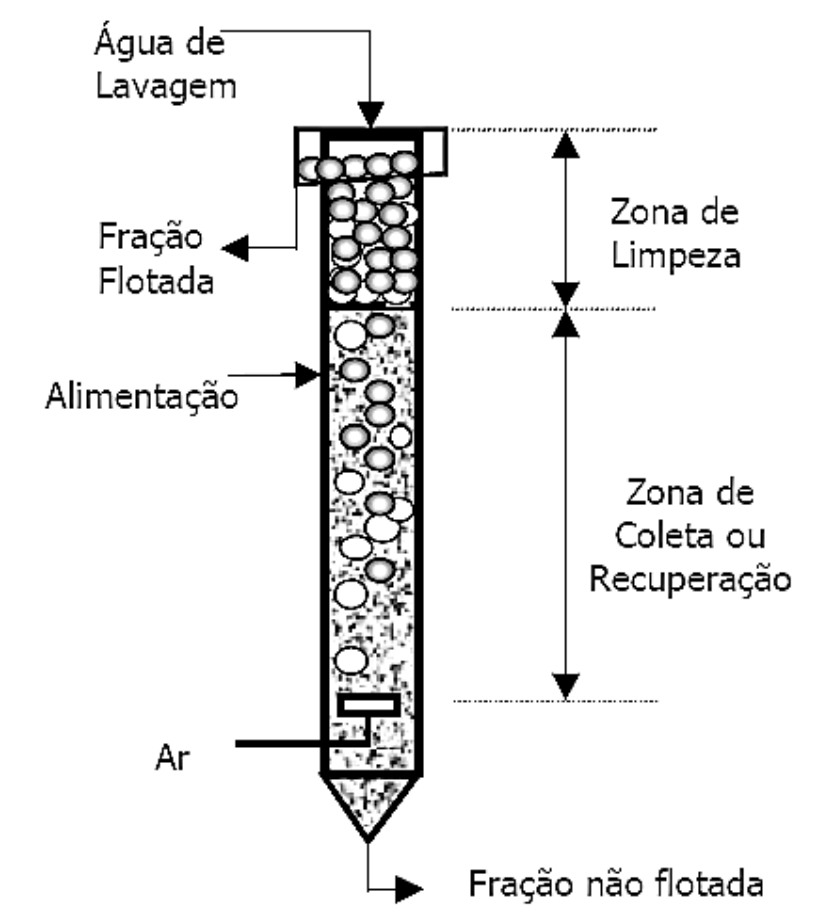

Figura 5: Representação esquemática da coluna de flotação. Fonte: Adaptado de Luz et al (2010).

\section{USO DE COLETORES ANIÔNICOS NA FLOTAÇÃO DE SILICATOS}

As aminas e os ácidos carboxílicos são alguns dos coletores aniônicos mais presentes na flotação de uma gama de minerais de todos os grupos mineralógicos, principalmente dos silicatos (Wills \& Finch, 2015).

Segundo Viana et al (2006), por meio de estudos de micro flotação (MF), medidas de potencial zeta (PZ) e espectroscopia infravermelha (IV), a adsorção dos coletores aniônicos em minerais silicáticos acontece através de quimissorção para $\mathrm{pH}>\mathrm{pHPZC}$ ( $\mathrm{pH}$ no ponto de carga zero), e fisissorção quando $\mathrm{pH}<\mathrm{pHPZC}$ (Tabela 2).

Tabela 2: Mecanismo de adsorção de coletores aniônicos em minerais silicáticos. Fonte: Adaptado de Viana et al (2006).

\begin{tabular}{c|c|c|c}
\hline Mineral & PZC & pH & Mecanismo Adsorção \\
\hline Quartzo & $1,4-2,3$ & 11 & Quimissorção \\
Microclina & $1,7-2,4$ & $2-6$ & Não flutua \\
Albita & $1,9-2,3$ & $2-6$ & Não flutua \\
Muscovita & $1,0-3,2$ & 8 & Quimissorção \\
Espodumênio & 2,6 & $4-8$ & Fisissorção/Quimissorção \\
Augita & $2,7-4,5$ & $3,8-11$ & Quimissorção \\
Berilo & $2,7-3,4$ & $<4$ & Fisissorção \\
Berilo & $2,7-3,4$ & $>4$ & Não flutua \\
Berilo & $2,7-3,4$ & 7 & Quimissorção \\
Turmalina & 3,9 & $5-10$ & Quimissorção \\
Granada & 4,4 & $<4$ & Fisissorção \\
Distênio & $6,2-7,9$ & $<4$ & Fisissorção \\
\hline
\end{tabular}


Os ensaios de bancada permitem analisar uma série de parâmetros que podem influenciar na flotação. A mistura de reagentes (coletores) é analisada em ensaios de laboratório e auxiliam na busca por condições otimizadas de operação industrial. A mistura de diferentes surfactantes conduz a sinergia do sistema, melhorando as condições de flotabilidade. Viana et al (2006) deixa claro os ganhos de flotabilidade do espodumênio quando há mistura dos coletores amina e sulfonato. Atribui-se o fato ao impacto que a mistura gera na concentração micelar crítica e na tensão interfacial.

\section{DEPRESSORES NA FLOTAÇÃO DE SILICATOS}

O amido é um dos principais depressores utilizados nas plantas de concentração de fluorita, apatita e minério de ferro. $O$ reagente é bastante atrativo em função de seu custo e biodegradabilidade. Segundo Turrer (2004), o Brasil possui uma alta produção de minério de ferro, o qual está associado com o quartzo ou outros minerais silicáticos. Deste modo, a flotação de silicatos torna-se fundamental para concentração dos minerais de interesse econômico, sendo os depressores (principalmente o amido) importantes para garantir a seletividade e uma melhor flotabilidade deste minerais.

A solubilização do amido é realizada a partir de um processo de gelatinização, que consiste em romper as ligações intragranulares através de um aumento de temperatura ou adição de reagentes químicos, como a soda cáustica (Turrer, 2004).

Segundo Souza e Magalhães (2016), o grau de gelatinização do amido tem influência direta no processo de flotação reversa de minério de ferro. Quanto maior a relação amido/soda cáustica, maior é a recuperação na flotação de sílica.

\section{ESPUMANTES NA FLOTAÇÃO DE SILICATOS}

Os espumantes são reagentes surfactantes utilizados para estabilizar as bolhas e, assim, melhorar o transporte da partícula coletada (Bulatovic, 2007). Entretanto, a utilização de espumantes na flotação dos silicatos não é muito usual, já que a amina tem a função de coletor e espumante. Normalmente os custos de utilização de coletores e espumantes como reagentes separados impedem sua aquisição (Araújo, Oliveira \& Dilva, 2005).

\section{APLICAÇÃO DA FLOTAÇÃO DE SILICATOS}

Os silicatos estão associados com a maior parte do minerais de interesse econômico. Logo, sua flotação é necessária para concentração do mineral útil, sendo descartados como rejeitos. Entretanto, a vermiculita é uma exceção, sendo o único silicato considerado como minério e concentrado pelo processo de flotação.

Consiste basicamente em um silicato de magnésio, com grande valor comercial, utilizada em diversas áreas, tais como: construção civil, agricultura, indústrias química, tintas, dentre outras. Sua utilidade depende, tanto da granulometria, quanto da pureza. O material fino é aplicado na construção civil, fabricação de fertilizantes e produção de alimentos para animais. A 
faixa de granulometria grosseira tem aplicação na horticultura, cultivo e desenvolvimento de sementes (Luz \& Lins, 2005).

\section{CONSIDERAÇÕES FINAIS}

Há uma tendência atual que busca a realização de mineração de forma sustentável. A flotação é um processo que consome grandes quantidades de água e, portanto, alternativas que reduzam este consumo são de fundamental importância na visão de Pinheiro, Baltar e Leite (2010).

Outro ponto importante é a alta utilização de reagentes coletores (amina) na flotação de silicatos. São compostos caros, e sua redução ou substituição por substâncias alternativas pode significar redução de custos no processo de flotação (Luz et al, 2010).

Portanto, estudar e entender minuciosamente o processo de flotação, considerando todas as suas variáveis operacionais e levando em conta as possibilidades de otimização torna-se fundamental na concentração de minerais, permitindo a manutenção de um empreendimento mineiro no mercado capitalista extremamente acirrado.

\section{REFERÊNCIAS}

Araújo, C. A.; Oliveira, J. F.; Dilva, R. R. R. (2005). Espumantes na Flotação Catiônica de Minérios de Ferro. Tecnologia em Metalurgia, Materiais e Mineração, 1 (3), 13-16.

Baltar, C. A. M. (2008). Flotação no tratamento de minérios. (1ª ed.). Recife: Departamento de Engenharia de Minas/ UFPE.

Bulatovic, S. M. (2015). Handbook of Flotation Reagents: Chemistry, Theory and Practice. (Vol. 1). Canada: Elsevier.

Chaves, A. P. (2013). Teoria e Prática do Tratamento de Minérios: A Flotação no Brasil (Vol. 4, 3a ed.). São Paulo: Oficina de Textos.

Departamento Nacional de Produção Mineral - DNPM (2016). Sumário Mineral 2015. Brasília: DNPM.

Fuerstenau, D. W.; Pradip. (2005). Zeta potentials in the flotation of oxide and silicate minerals. Advances in Colloid and Interface Science, 9-26.

Gancev, R. K. (2009). Concentração de bauxita por flotação reversa. Dissertação de mestrado, Escola Politécnica da Universidade de São Paulo, São Paulo, São Paulo, Brasil.

Gupta, A.; Yan, D. S. (2006). Mineral processing design and operation: an introduction. (First edition). Elsevier Science.

Klein, C. (2008). The 23rd Edition of the Manual of Mineral Science: after James D. Dana. John Wiley \& Sons.

Luz, A. B.; Lins, F. A. F. (2005). Rochas e minerais industriais: Usos e especificações. (1a ed.). Rio de Janeiro: CETEM/MCT.

Luz, A. B.; Sampaio, J. A.; França, C. A. F. (2010). Tratamento de minérios. (5a ed). Rio de Janeiro: CETEM/MCT. 
Manser, R. M. (1975). Handbook of Silicate Flotation. Stevenage: Warren Spring Laboratory.

Moon, K. S.; Fuerstenau, D. W. (2003). Surface crystal chemistry in selective flotation of spodumene $\left(\mathrm{LiAl}\left[\mathrm{SiO}_{3}\right]_{2}\right)$ from other aluminosilicates. International Journal of Mineral Processing, 72, 11-24.

Mular, A. L.; Halbe, D. N.; Barratt, D. J. (2002). Mineral Processing Plant Design, Practice, and Control: Proceedings. (Vol. 1). Colorado/USA: SME.

Pinheiro, V. S.; Baltar, C. A. M.; Leite, J. Y. P. (2010). Influência da qualidade da água na flotação de quartzo com amina. Holos, 26 (3), 28-36.

Queiroz, G. M. (2003). Estudo da cinética de flotação de apatita em coluna. Dissertação de Mestrado, Universidade Federal de Uberlândia, Uberlândia, Minas Gerais, Brasil.

Souza, A. C.; Magalhães, D. G. A. (2016). A Influência do Grau de Gelatinização do Amido de Milho no Processo de Flotação Reversa de Minério de Ferro. Tecnologia em Metalurgia, Materiais e Mineração, 13, 141-147.

Turrer, H. D. G. (2004). Utilização de Poliacrilamidas de Alto Peso Molecular na Flotação Catiônica Reversa de Minério de Ferro. Dissertação de Mestrado, Universidade Federal de Minas Gerais, Belo Horizonte, Minas Gerais, Brasil.

Viana, P. R. M.; Araujo, A. C.; Peres, A. E. C.; Valadão, G. E. S. (2006). Adsorção de misturas de coletores em silicatos. Revista Escola de Minas, 59 (4), 421-425.

Wills, B. A.; Finch, J. A. (2015). Mineral Processing Technology: An Introduction to the Practical Aspects of Ore Treatment and Mineral Recovery. (8a ed). Butterworth-Heinemann. 